\title{
Investigation and Analysis on Library Service Quality
}

\author{
QiYun, Zhang
}

\author{
A Case Study in Tianjin Polytechnic University
}

\begin{abstract}
Since the development of the information technology, there have been great changes in the functions and the nature of university library. This paper takes Tianjin Polytechnic University as a case study and attempts to make an investigation and analysis on the service quality of library by questionnaire. Based on SPSS 16.0 statistical analysis, this study revealed the status quo of readers' satisfaction on the library service, analyzed the problems and made related strategies and suggestions in order to facilitate and enhance the library service quality.
\end{abstract}

Key words: - library service service quality readers'satisfaction investigation and analysis

\section{INTRODUCTION}

University library works as the information service center for students and teachers of a university and the services provided by a university library can be classified into many categories ranging from text books to advanced research papers in different formats such as paper-based resources, digital documents, compact disks and digital versatile disks. As the advent of the 21st century economic globalization, the information network and educational internationalization, university libraries have entered a new era and undergone great changes. Much change has also occurred in the readers' needs of the university and the needs get multipliable and diversified.

As everyone knows that the reader is the footstone of the library, that is to say, the library will lose its value without the readers' satisfaction. So, library service has a pivotal position in the university and plays a more and more important role in the library building. All the goals of the library are to meet the readers' needs to the literatures of all kind.

Since Tianjin Polytechnic University moved from the original site to the new library, the overall environment, installation arrangement, literature materials and the human resources changed a lot. Whether the service quality of library could meet the readers' requirements or not need an investigation. This research is made through the survey and analysis of the questionnaire from readers. The questionnaire is designed to answer what the readers' satisfactory is, how to access readers' satisfaction and how to improve readers' satisfactory degree of university library service. Through the investigation, the problems and shortcomings are found and the author proposes some possible solutions to improve readers' satisfaction in the current library service. The purpose of this paper is to clarify the orientation for future library service work in order to offer readers correct service and right information.

This paper is organized as follows. In Section 2, the author designs the questionnaire. In section 3, the questionnaire is presented and analyzed. In section 4, some suggestions and proposes on how to improve readers' satisfaction were offered. Section 5 concludes the paper.

\section{THE DESIGN OF READERS' QUESTIONNAIRE}

This part is composed of the research questions, information of the subjects, instruments and the 
procedure. The next is the research questions.

\subsection{Research questions}

The objective of this investigation is to make clear the following questions:

(1). What is the readers' current satisfactory degree of university library service?

(2). How to improve the future library service work?

\subsection{Subjects}

This research consists of two groups of subjects. Both of the two groups are from Tianjin Polytechnic University. One group is composed of 50 college teachers. The teachers are chosen from the Department of Finance, Department of Law, Department of Art, Department of English and the Department of Computer Science. They have worked in Tianjin Polytechnic University ranging from 3 to 10 years. All of them volunteer to be involved in this research. Look at the following table.

Table 1 The information of teachers subjects

\begin{tabular}{|c|c|}
\hline College teachers & number \\
\hline Department of Finance & 9 \\
\hline Department of Law & 11 \\
\hline Department of Art & 6 \\
\hline Department of English & 16 \\
\hline Department of Computer Science & 8 \\
\hline
\end{tabular}

The other group is made of 250 college students which are freshmen, sophomore, junior, senior and master from different departments. All the subjects have passed CET 4and some of them have passed CET 6 . Therefore, it is supposed that they are similar in English proficiency, which can make the result of the present study more valid and reliable. The detailed information about these subjects is in the following table (table 2).

Table 2 The information of students subjects

\begin{tabular}{|c|c|}
\hline College students & number \\
\hline freshmen & 50 \\
\hline sophomore & 50 \\
\hline junior & 50 \\
\hline senior & 50 \\
\hline master & 50 \\
\hline
\end{tabular}

\subsection{Instruments}

A self designed questionnaire was conducted in this study. The questionnaire consists of 4 parts. The first part includes 10 items, which are used to test the subjects' satisfaction degree of the accession of literature resources. The second part is about the library environment and installation, including 10 items. The third part is to detect the satisfaction degree of service effect and includes 10 items. The last part is about the innovation service of the library with 5 items.

The subjects are asked to choose one answer from the 5-point scale formats. The five answers are as follows: (1) strongly dissatisfied (2) dissatisfied (3) satisfied (4) more satisfied (5) the most satisfied. Scale one means the subjects are strongly dissatisfied with the statement of the item, and is scored 1 . Scale 5 is scored 5 , which represents the subjects are greatly satisfied with the statement. State2, 3 and 4 are in the middle of the 
range with scores 2,3 and 4 respectively.

\subsection{Procedure}

The research was conducted in June, 2013. The questionnaires on students subjects were carried out first. All the subjects were given 10 minutes to answer the questions in the questionnaire. In order to keep the students' patience and make the answers reliable, the author gave little presents to the students involved and also gave directions to them. As to the teachers subjects, the author gave out the questionnaires after they had a meeting. Each of them treated the questionnaire seriously. At last, the Statistical Package for Social Sciences (SPSS) program was used to analyze the quantitative data which were collected from the questionnaire.

\section{THE ANALYSIS OF THE QUESTIONNAIRE}

This part deals with the statistical results of the data collected before. Honestly speaking, the questionnaire was conducted very smoothly. All the teachers' 50 copies of questionnaire were taken back and found valid after careful examination. The students' 250 copies of questionnaire were also returned and found 228 of them were valid. The following is the questionnaire.

3.1 Designed questionnaire

\begin{tabular}{|c|c|}
\hline $\begin{array}{l}\text { accession of } \\
\text { literature resources }\end{array}$ & $\begin{array}{l}\text { A1.Library books (paper-based books and digital books) can meet readers' } \\
\text { needs. } \\
\text { A2.Current magazines, newspapers and periodicals can meet readers' } \\
\text { requirements. } \\
\text { A3.Past magazines, newspapers and periodicals can meet readers' } \\
\text { requirements. } \\
\text { A4.Readers can find and get the books from the shelves easily and } \\
\text { conveniently. } \\
\text { A5.Interlibrary loan and document delivery service is timely and efficient. } \\
\text { A6. Readers can obtain the new digital resources in time. } \\
\text { A7. Opening hours of the library is reasonable and convenient. } \\
\text { A8.Overdue books regulations, the number of borrowed books and the time } \\
\text { limit to borrowed books are reasonable. } \\
\text { A9. Cross discipline can meet readers' needs. } \\
\text { A10. Readers can get the information they want without help from others in } \\
\text { the library. }\end{array}$ \\
\hline $\begin{array}{l}\text { library environment } \\
\text { and installation }\end{array}$ & $\begin{array}{l}\text { B1.Library overall environment is neat and comfortable. } \\
\text { B2.Library installation arrangement is reasonable. } \\
\text { B3.Readers can study and think quietly in library. } \\
\text { B4.Library guidance and marks are obvious and clear. } \\
\text { B5.Enough soft wares and hard devices are available in library. } \\
\text { B6.Printing, copying and duplicating are convenient in library. } \\
\text { B7.Library literature resources are distributed reasonably and are easy to be } \\
\text { found. } \\
\text { B8. There are sufficient seats and power sockets in the library. } \\
\text { B9. The temperature and the ventilation of the library are suitable. } \\
\text { B10. There is wireless network in the library and the wireless network is } \\
\text { consistent. }\end{array}$ \\
\hline $\begin{array}{c}\text { satisfaction degree } \\
\text { of service effect }\end{array}$ & $\begin{array}{l}\text { C1. Librarians treat readers friendly and patiently. } \\
\text { C2. Librarians dress neatly and behave politely. } \\
\text { C3. Librarians have enough knowledge and skills to deal with readers' } \\
\text { problems. } \\
\text { C4. Librarians response to readers' questions quickly. } \\
\text { C5. Librarians deal with readers' problems sincerely and provide satisfactory } \\
\text { help for readers. } \\
\text { C6. Library response to readers' criticisms and suggestions and improves them }\end{array}$ \\
\hline
\end{tabular}




\begin{tabular}{c|l}
\hline & in time. \\
& C7. Training courses and knowledge lectures which are helpful to readers are \\
& usually opened in library. \\
C8. Library provides personalized service for readers. \\
C9. Library provides the service of reference, consulting and handling readers' \\
queries online. \\
C10. Library provides the service of document delivery and sci-tech novelty \\
searching.
\end{tabular}

\subsection{Statistics of questionnaire}

\begin{tabular}{c|c|c}
\hline Items & $\begin{array}{c}\text { Mean of } \\
\text { teachers } \\
\text { subjects }\end{array}$ & $\begin{array}{c}\text { Mean of } \\
\text { students subjects }\end{array}$ \\
\hline A1 & 3.221 & 3.440 \\
A2 & 3.129 & 3.550 \\
A3 & 3.229 & 3.337 \\
A4 & 3.112 & 3.071 \\
A5 & 3.109 & 3.118 \\
A6 & 3.338 & 3.342 \\
A7 & 3.663 & 3.651 \\
A8 & 3.449 & 3.554 \\
A9 & 3.004 & 3.339 \\
A10 & 2.991 & 2.883 \\
B1 & 3.789 & 3.663 \\
B2 & 3.550 & 3.432 \\
B3 & 3.667 & 3.079 \\
B4 & 3.489 & 3.789 \\
B5 & 3.559 & 3.650 \\
B6 & 3.660 & 3.880 \\
B7 & 3.219 & 3.297 \\
B8 & 3.883 & 3.990 \\
B9 & 3.667 & 3.771 \\
B10 & 2.772 & 2.072 \\
C1 & 3.332 & 3.079 \\
C2 & 3.686 & 3.558 \\
C3 & 3.449 & 3.308 \\
C4 & 3.332 & 3.317 \\
\hline
\end{tabular}




\begin{tabular}{l|l|l}
\hline C5 & 3.346 & 3.332 \\
C6 & 3.317 & 3.008 \\
C7 & 3.339 & 3.347 \\
C8 & 2.917 & 2.863 \\
C9 & 3.039 & 2.887 \\
C10 & 3.440 & 3.229 \\
D1 & 2.707 & 3.076 \\
D2 & 3.150 & 3.225 \\
D3 & 3.204 & 3.129 \\
D4 & 3.041 & 3.109 \\
D5 & 3.145 & 3.205 \\
\hline
\end{tabular}

\subsection{Analysis of the questionnaire}

As shown in the first statistic table, we can see that both the teachers and the students are satisfied with the opening hour of the library and library lending regulations. However, the mean of A1, A2, A3, A9 of the teachers subjects are much lower than students subjects. Teachers are relatively not satisfied with the library resources including paper-based resources and digital resources. This is because what teachers need are very professional. Their research is very frontier. The books they need are not easy to purchase. But for the students, the resources they need are very general and fundamental. The resources in the library are nearly can meet the students' needs. The mean of A10 are the lowest value both in the teachers subjects and students subjects with the score 2.991, 2.883 respectively. Both the teachers and students find it hard to get the information they want. This is because paper-based books are usually put to the wrong places after using. These mistakes can't be found and corrected by librarians easily because of so many books. A reader who needs a resource that has been put in the wrong position accidentally may hardly find it.

As for the second statistic table, we can see that both the teachers and students are much more satisfied with the overall environment and library installation. This is because the library in Tianjin polytechnic university is a new built library. It is very spacious, bright and grandeur. Perhaps just because it is very new, the wireless network has not been set up completely. Besides the mean of B10, the mean of B7 is second lowest value both in the teachers subjects and students subjects. The teachers and students are relatively not satisfied with the resources distribution in the library. This is because library staff didn't reconsider the allocation of paper-based resources. The pattern of resources may change from time to time and the resources should be reallocated according to the readers' behaviors and needs.

The third statistical table is about the library service effect. We can see that the mean of C8 is the lowest value both in the teachers subjects and students subjects. Both the teachers and students are not satisfied with the personalized service. This is because there are so many teachers and students in the university and the number of the librarians is very limited. On the other hand, the protection of reader information privacy made the individualized service work develop slowly. The mean of C6 is much lower than other items. Both teachers and students think Library doesn't response to readers' criticisms and suggestions timely. Readers' recommendation should be taken into account, because it is a directly way to know what readers really need. Library should emphasis on readers' recommendation. Besides C6 and C8, the mean of C9 is also low. Library should provide the service of reference and deal with readers' questions in time. As for the students subjects, the mean of $\mathrm{C} 1$ and $\mathrm{C} 3$ are also much lower. Librarians can't treat them politely and patiently. They think librarians 
don't have much knowledge to deal with their questions. So, library should enhance librarians training and educating.

The last part is about the innovation service. We can see that the mean of D1 is the lowest both in teachers subjects and students subjects. Teachers and students complain that they can't get the library digital resource at home. When they need some digital resources, they have to go to the university to get the information. On the one hand, this is because the library wants to preserve the digital resources in case of some people downloading the digital resources deliberately and balefully. On the other hand, it is because of the shortage of scientific and technological development. The mean of D4 is also lower than other items. Library should build a micro-blogging interactive platform for readers in order to communicate with the librarians conveniently.

\section{SUGGESTIONS AND PROPOSES ON LIBRARY SERVICE}

Readers' need is the power source of the continuous innovation of library service, and is also one of the most important driving factors of the sustainable development of the library. With the development of the information technology, the requirements of the readers are driven to change constantly. The multilevel diversity and individuation of readers' needs has brought both pressure and impetus to the library. The author gives some possible solutions to enhance the library service in the following part.

\subsection{Selecting and allocating paper-based resources efficiently}

Even though many digital resources have been introduced in most universities in China, traditional paper-based resources still share major percentage in the whole library resources. As stated in part 3, some resources in the library may not be needed by the user while the others may be really needed by the user but not available in the library or the related resources are not enough. Some books are sometimes mistakenly put to the wrong places after using, and these mistakes can't be found and corrected in time. The author gives some solutions in order to solve these problems.

\subsubsection{Selecting and purchasing resources effectively}

In the current library, library staffs select and purchase paper-based resources just depending on their own knowledge and experience. Some university libraries use the resources lending records to test the resource selection and purchase plan, but it is not enough. Here, the author proposes to utilize some evaluation parameters to check whether the paper-based resources are used effectively. The next is the formula.

$$
A=\frac{\text { the circulation number of a resource/the total circulation number of all the resources }}{\text { the volume of a resource/the total volume of all the resources }}
$$

The value of $\mathrm{A}$ attempts to achieve to be 1 . If the value of $\mathrm{A}$ is much lower or much higher than 1 , we need to check whether the resources are properly allocated in the library or there is any resource never or rarely used. Through this value, we can check what kind of resources the users need and whether the resources in the library satisfy the users' requirements.

\subsubsection{Reallocating paper-based resources}

Since the users' needs change much quickly, the pattern of resource allocation should change from time to time. We propose to periodically reconsider the allocation of paper-based resources according to the users' behaviors and requirements in a university. The resource allocation can be determined by the ratio of the circulation number of the resources or by the usage of the information such as the lending and returning place and the user department. So, the paper-based resources should be reallocated timely depending on the user requirement pattern. 


\subsubsection{Using the advanced IT technologies}

Since the books are also put to the wrong place after usage and the mistakes can't be found timely. Another user may hardly find the resource when he needs it. Here, the author proposes to use Radio frequency identification (RFID) tags. A RFID tag is a tiny-chip and embedded in paper-based resources. We can use hand-held tag reader or set the book-shelf reader for management of paper-based resources. When a book with a embedded RFID tag is removed from its original storage shelf, the librarian can know this immediately. This technology also can help us to trace how each kind of resources is used by users.

\subsection{Enhancing all librarians' service training and education}

In the era of the information age, the role of librarians has changed a lot, transforming from "Information Gatekeeper" to "Information Navigator", "Knowledge Specialist", "Information Manager". This requires the librarians not only to have the capability of technique, management and research, but also to possess good personal qualities such as the good communication ability, the appreciation features that can show the working performance and competitiveness in new working environment. So, it is of great need to establish a lasting training system and reinforce librarians' comprehensive ability. Effective and sustainable training system is helpful for the improvement of librarians' service awareness, vocational skill and comprehensive quality. The form of training can be full-time study, expert lectures and status competition, all of which can help librarians to improve service ability and reduce working mistakes. At the same time, other training aspects such as polite manners, specification language, psychological quality, mind training and service skill should also be strengthened in order to promote librarians' contingency ability in dealing with different circumstances.

Meantime, the librarians should be out of the library and deep into the department and the research institutes to come to the readers' sides. Through communicating with the readers, librarians can learn readers' expectations and needs, especially the deep and potential demands. Paying close attention to readers' needs and absorbing readers' wisdom and strength can not only provide more targeted service, but also promote the optimum development of the library through the readers' assistance and participation.

\subsection{Focus attention on readers' recommendation}

Librarians can learn readers' expectation and demands directly through reader recommendation. In the following, the author proposes to take reader recommendation in the resource management and introduces three recommendation approaches.

The first reader recommendation approach is very directly. A reader can give a recommendation through the web interface to the library management system on the topics that the reader is interested or the reader can input the information about the resource that is not available in the library. When the reader can't find the required resource, he can click on the link to the recommendation page and input the recommendation details such as the title, the author and the publisher information. The librarian can use these recommendations to make their purchase plans.

The second reader recommendation approach is that a reader is allowed to have the right to submit recommendations or comments on what he has read. A resource preferred by a reader may also be preferred by many others and the comments of previous readers on the resources usually have significant impact on the latter readers. Therefore, many other readers select and choose resources in the light of the comments of previous readers. This can save a lot of time.

The third reader recommendation approach is about the library management system. The management system can show a reader some recommended resources related to the topics the reader wants to find when the 
targeted resource is unavailable in the library. The recommendation to the topic may consist of a list of the resources by the same author or other resources which are very closely related to the requested topics.

As for the reader information, it can be obtained from the library management system. Some experts invented the data mining technique, which is an efficient way to analyze the collected reader information and can give a good solution automatically.

\subsection{Make full use of scientific and technological progress}

As the library investigation above suggests some readers complain that they can't get the information at home. If they want to obtain the digital information, they have to come to their office. So, the traditional service should be updated in order to make the library service break through the limit of space. Library digital service should be everywhere at any time. Here, the author proposes to use web 2.0 or lib 2.0. Web 2.0 is a new generation model of the internet. This new internet model can apply and copy the relevant content of the library to anywhere according to the demands of the readers at any time (Wu Jianjun, 2010). It advocates the library to break the passive service model, to go out actively and participate in readers' lives. That means where the readers are, where the library is. The library will exceed the concept of "No fencing library". The library is everywhere and has no barrier. Compared with the traditional service, it will make the library service more humanism.

The advent of web 2.0 opens the new era of the library service and we hope to apply this new model to the library soon.

\section{CONCLUSION}

Service is the eternal theme of the library work, and is also the originally standing foundation of the library. This paper investigates the current library services provided in Tianjin polytechnic university. Through this survey, many problems existing in the current university libraries are disclosed. The problems are wrong allocation of paper-based resources, low quality of the information integration based on network, relative lag of service method, shortage of librarian training and education. The author then proposes some possible solutions to deal with these problems. Firstly, standardize paper-based resources. Secondly, enhance librarians' service training and education. Thirdly, put emphasis on reader recommendation. Fourthly, utilize advanced information technologies in library management. Through these solutions, the user-oriented service ideology could be completely set up.

\section{REFERENCES}

[1] Cuihong Hu. (2011). Study and Application the Performance Evaluation System Based on Network Technique. International Conference on Engineering Management.

[2] Hong yue, Chang Lin. (2010). Development of Library Subject Service System in the Network Environment. International Conference on Industrial Mechatronics and Automation.

[3] Jia Ji'e. (2012). Study on Readers' Satisfaction on Library Service Quality. Journal of Modem Information.

[4] Lucia Tsui, Sidney Cheng, Ivan Chan. (2003). Digital Library service Initiative of the Hong Kong Institute of Education Library. Journal of Shanghai Jiaotong University.

[5] Ma Jiangbao. (2012). The analysis of the Survey on Library Service Quality in Guangong Communication Polytechnic. Journal of Guangdong Communications Polytechnic.

[6] Song Deng, Jun Wang. (2010). New Approach of University Library Journal Service in Chinese University. International Conference on Management Science and Engineering. 
[7] Wu Jianjun. (2010). The Study on Library Service's Transformation and Innovation based on Web 2.0. International Conference on Broadcast Technology and Multimedia Communication.

[8] Xiao-qing Li, Jing-zhong Yang. (2012). Application of LibQUAL ${ }^{+\mathrm{TM}}$ and FAHP on Public Library Service Quality Evaluation. International Conference on Industrial Engineering and Engineering Management.

Qiyun Zhang was born in Heibei, China in 1982. She received her M.A. degree in linguistics from Tianjn Polytechnic University in March, 2011.

She is currently a librarian in Tianjin Polytechnic University, Tianjin, China. Her research interests include psycholinguistics, Second Language Acquisition and Library Management. 